\title{
Quitosana reduz a severidade da antracnose e aumenta a atividade de glucanase em feijoeiro-comum
}

\author{
Robson Marcelo Di Piero(1) e Marcos Venicius Garda(1)
}

\begin{abstract}
(1)Universidade Federal de Santa Catarina, Centro de Ciências Agrárias, Departamento de Fitotecnia, Laboratório de Fitopatologia, Caixa Postal 476, CEP 88034-001 Florianópolis, SC. E-mail: robson@cca.ufsc.br, garda_floripa@yahoo.com.br
\end{abstract}

Resumo - O objetivo deste trabalho foi avaliar o controle da antracnose em feijoeiro-comum pela aplicação de quitosana. A quitosana foi pulverizada em plantas de feijão-comum, em diferentes concentrações, no estádio V3, em casa de vegetação. As plantas foram também submetidas à inoculação de Colletotrichum lindemuthianum. A dose de $9 \mathrm{mg}$ de quitosana por planta propiciou redução em mais de 50\% na severidade da antracnose e não causou fitotoxicidade. O efeito protetor foi local e mais intenso no intervalo de tempo de 4 dias entre tratamento e inoculação. Observou-se redução significativa no crescimento micelial e inibição total da germinação de esporos de $C$. lindemuthianum, quando se utilizou o polissacarídeo a $1 \mathrm{mg} \mathrm{mL}^{-1}$ e $80 \mu \mathrm{g} \mathrm{mL}^{-1}$, respectivamente. Em folhas do feijoeiro, a quitosana provocou o aumento na atividade de glucanase. Quitosana apresenta propriedades antifúngicas contra $C$. lindemuthianum, bem como potencial para induzir resistência à planta, e pode ser uma alternativa para o controle da antracnose do feijoeiro.

Termos para indexação: Phaseolus vulgaris, Colletotrichum lindemuthianum, antibiose, indução de resistência, proteínas relacionadas à patogênese.

\section{Chitosan reduces the anthracnose severity and increases the glucanase activity in common bean plants}

\begin{abstract}
The objective of this work was to evaluate the effect of chitosan on common bean (Phaseolus vulgaris) anthracnose. Different concentrations of chitosan suspension were sprayed on plants at V3 stage, in greenhouse; plants were also infected with Colletotrichum lindemuthianum. The concentration of $9 \mathrm{mg}$ per plant reduced the anthracnose severity in more than $50 \%$, without causing any toxic effect on bean plants. The protecting effect was local and more intense in a time interval of 4 days between treatment and inoculation. Mycelium growth reduction and spore germination inhibition of $C$. lindemuthianum were observed, when chitosan was used at $1 \mathrm{mg} \mathrm{mL}^{-1}$ and $80 \mu \mathrm{g} \mathrm{mL} \mathrm{m}^{-1}$, respectively. Chitosan increased the glucanase activity in bean leaves. Chitosan presents antifungal properties against $C$. lindemuthianum, as well as potential to induce resistance on bean plants. Therefore, the plant spraying with chitosan can be an alternative to control anthracnose.
\end{abstract}

Index terms: Phaseolus vulgaris, Colletotrichum lindemuthianum, antibiosis, induced resistance, pathogenesisrelated proteins.

\section{Introdução}

A antracnose, provocada pelo fungo Colletotrichum lindemuthianum (Sacc. \& Magn.) Scrib., é uma das doenças de maior importância da cultura do feijoeiro-comum (Phaseolus vulgaris L.), e afeta, em todo o mundo, as cultivares suscetíveis estabelecidas em locais com temperaturas moderadas e alta umidade relativa (Bianchini et al., 2005). No Brasil, é prevalente nos principais estados produtores, tais como o Rio Grande do Sul, Santa Catarina, Paraná, São Paulo, Minas Gerais e Bahia.
A medida ideal para o controle da doença é a utilização de variedades resistentes. No entanto, a alta variabilidade do agente causal, expressa por um grande número de raças, dificulta a obtenção de variedades com resistência durável, e força os produtores a proteger suas lavouras através do emprego de fungicidas, algumas vezes de maneira indiscriminada.

A preocupação com o ambiente e com a presença de resíduos de agrotóxicos nos alimentos e a exigência cada vez maior do mercado consumidor de adquirir produtos saudáveis, obtidos a partir de tecnologias de baixo impacto ambiental, têm levado os pesquisadores

Pesq. agropec. bras., Brasília, v.43, n.9, p.1121-1128, set. 2008 
a buscar medidas alternativas para o controle de doenças de plantas, tais como o emprego do controle biológico e da indução de resistência.

A indução de resistência pode ser definida como uma resistência dinâmica, baseada nas barreiras estruturais e bioquímicas da planta, induzida por inoculação prévia ou concomitante com um indutor. Os indutores são microrganismos saprofíticos, metabólitos microbianos, extratos de plantas, agentes químicos, entre outros (Manandhar et al., 1998). O estado induzido é demonstrado por um aumento na síntese de produtos de defesa vegetal, tais como: proteínas relacionadas à patogênese (quitinases, glucanases, peroxidases), fitoalexinas e compostos sinalizadores (Heil \& Bostock, 2002).

Entre os agentes que possuem propriedades antibióticas e ativadoras de mecanismos de defesa em plantas encontram-se a quitina e a quitosana. Quitina é um polissacarídeo constituído por uma seqüência linear de N-acetilglucosamina, com estrutura semelhante à da celulose (Signini, 2002). A quitina tem como principais fontes naturais as carapaças - de crustáceos, notadamente caranguejo, camarão e lagosta -, que representam $15-20 \%$ do peso, e é também encontrada em insetos, moluscos e na parede celular de fungos.

A quitosana é uma forma desacetilada de quitina, com poli D-glucosamina como bloco construtor. Por se tratar de polímero biodegradável, extremamente abundante e atóxico para os animais (Shahidi et al., 1999; Rhoades \& Roller, 2000), a quitosana tem sido proposta como material atraente para usos diversos, principalmente em engenharia, biotecnologia e medicina. Em termos agrícolas, a quitosana tem sido pesquisada para se determinar sua habilidade no aumento da tolerância de plantas a estresses (Lee et al., 1999) e na ativação de respostas de defesa, de forma a se protegerem as espécies vegetais contra microrganismos fitopatogênicos (Benhamou, 1996). A indução de resistência com a utilização de quitosana foi demonstrada em culturas como pepino (Cucumis sativus L.), trigo (Triticum aestivum L.), ervilha (Pisum sativum L.), amendoim (Arachis hypogaea L.) e arroz (Oryza sativa L.) contra Pythium aphanidermatum (Edson) Fitzp., Alternaria alternata (Fr.) Keissl., Fusarium gramineareum Schwabe, Fusarium solani f.sp. pisi Snyd. \& Hans., Fusarium oxysporum f.sp. apii Snyd. \& Hans. e Pyricularia grisea (Cooke) Sacc. (Sathiyabama \& Balasubramaniam, 1998; Bhaskara Reddy et al., 1999; Lin et al., 2005).
O objetivo deste trabalho foi avaliar o controle da antracnose em feijoeiro-comum, com o uso de quitosana, e estudar os mecanismos de ação envolvidos num possível controle dessa doença, de maneira a possibilitar a criação de uma alternativa aos fungicidas sintéticos.

\section{Material e Métodos}

Para a obtenção das plantas, sementes de feijoeirocomum (Phaseolus vulgaris) da cultivar IPR Uirapuru, fornecidas pela Epagri, Estação Experimental de Caçador, SC, foram semeadas em vasos de plástico de $3 \mathrm{~L}$ com mistura de solo e matéria orgânica $(4: 1)$. Os vasos foram mantidos em casa de vegetação, do Departamento de Fitotecnia, do Centro de Ciências Agrárias (CCA), da Universidade Federal de Santa Catarina (UFSC), em Florianópolis, SC.

Com relação ao fitopatógeno, o isolado de Colletotrichum lindemuthianum raça 73 (Loffaguen et al., 2005) foi utilizado nos ensaios. O isolado pertence à micoteca do Laboratório de Fitopatologia, CCA, UFSC e é proveniente de vagens de feijão infectadas, coletadas na região do Alto Vale do Itajaí, Santa Catarina. Para induzir o fungo à esporulação, pedaços de meio de cultura batata-dextrose-ágar (BDA) com micélio do fitopatógeno foram repicados para tubos de ensaio que continham vagem de feijão esterilizada, mantidos a $25^{\circ} \mathrm{C}$, sob luz fluorescente constante.

A quitosana com $85 \%$ de desacetilação é proveniente da China (lote de fabricação: HP20051026) e apresenta fórmula molecular $\left(\mathrm{C}_{8} \mathrm{H}_{13} \mathrm{NO}_{5}\right)$ n. A suspensão do polissacarídeo foi preparada pela dissolução em $\mathrm{HCl}$ 0,05 N com agitação constante e correção do $\mathrm{pH}$ para 5,6 com $\mathrm{NaOH} 2 \mathrm{M}$.

AproteçãodeplantasdefeijoeirocultivarIPRUirapuru contra a antracnose foi feita pela pulverização, no estádio V3, com $4 \mathrm{~mL}$ por planta de uma suspensão de quitosana nas concentrações $0,6,12,18,24,36$ e $48 \mathrm{mg}$ por planta. Após 5 dias, essas plantas foram submetidas à inoculação de $4 \mathrm{~mL}$ por planta de uma suspensão de $C$. lindemuthianum a $5 \times 10^{5}$ esporos $\mathrm{mL}^{-1}$. Os tratamentos com quitosana foram feitos em toda a parte aérea das plantas, com exceção do trifólio mais novo de cada planta, que foram cobertos com saco de plástico durante a aplicação do tratamento, para a posterior verificação de proteção sistêmica. Logo após a inoculação, as plantas foram colocadas em câmara 
úmida por 48 horas. Foram realizadas cinco repetições por tratamento, e cada repetição foi constituída por um vaso com três plantas.

A avaliação da severidade da doença, realizada aos 15 dias após a inoculação, foi baseada em uma escala descritiva proposta por Rava et al. (1993), com notas de 1 a 9, em que 1 representa a ausência de sintomas e 9 , a mortalidade da planta. O experimento foi realizado duas vezes.

Com base nos resultados dos ensaios anteriores, estudou-se a influência do intervalo de tempo entre o tratamento com quitosana e a inoculação do fitopatógeno sobre a severidade da antracnose. Para tal, as plantas de feijão foram tratadas com: I) água destilada (controle); II) $\mathrm{HCl}$ 0,05 N, pH 5,6 (segundo controle); III) quitosana a $9 \mathrm{mg}$ por planta (Q9), aplicada uma única vez, 4 dias antes da inoculação (DAI) do C. lindemuthianum; IV) Q9 aplicada uma única vez, 1 DAI; V) Q9 aplicada aos 4 e 1 DAI; VI) quitosana a $18 \mathrm{mg}$ por planta (Q18), aplicada uma única vez, 4 DAI; VII) Q18 aplicada uma única vez, 1 DAI; VIII) Q18 aplicada aos 4 e 1 DAI. A manutenção das plantas, o estádio no período da inoculação, o número de repetições e a forma de avaliação dos resultados seguiram a metodologia descrita anteriormente. Este experimento foi realizado duas vezes.

$\mathrm{O}$ efeito de quitosana sobre a atividade de glucanases e peroxidases em plantas de feijoeiro foi estudado em amostras vegetais de dez discos foliares de $1 \mathrm{~cm}$ de diâmetro, obtidos do primeiro trifólio de plantas de feijão no estádio V3, coletados a partir dos seguintes tratamentos: I, II e III, plantas apenas com pulverização de água destilada, de $\mathrm{HCl} 0,05 \mathrm{~N}(\mathrm{pH} 5,6)$ e de quitosana (18 $\mathrm{mg}$ por planta), respectivamente; IV, $\mathrm{V}$ e VI, plantas com pulverização de água destilada, de $\mathrm{HCl} 0,05 \mathrm{~N}(\mathrm{pH} \mathrm{5,6)}$ e de quitosana (18 mg por planta), respectivamente, e com inoculação de C. lindemuthianum. A inoculação foi realizada com suspensão de $5 \times 10^{5}$ esporos $\mathrm{mL}^{-1}, 3$ dias após a pulverização nos tratamentos IV, V e VI. Os tempos de amostragem foram 0, 2, 4 e 6 dias após os tratamentos. Para cada tempo, em cada tratamento, foram realizadas 5 repetições.

As amostras foram maceradas em presença de nitrogênio líquido ehomogeneizadas em $4 \mathrm{mLde}$ tampão acetato de sódio $0,1 \mathrm{M}(\mathrm{pH}$ 5). Após a homogeneização as amostras foram centrifugadas a $20.000 \mathrm{~g}$ por $30 \mathrm{~min}$, a $4^{\circ} \mathrm{C}$, e o sedimento foi descartado. A atividade de beta-1,3-glucanase foi avaliada no sobrenadante. Para tal, $50 \mu \mathrm{L}$ do sobrenadante foram adicionados a $450 \mu \mathrm{L}$ de laminarina $\left(1,5 \mathrm{mg} \mathrm{mL}^{-1}\right)$ em tampão acetato de sódio $0,1 \mathrm{M}(\mathrm{pH}$ 5). A reação foi conduzida a $44^{\circ} \mathrm{C}$ durante $60 \mathrm{~min}$, em banho-maria, sem agitação. Após o período de incubação, os açúcares redutores formados foram quantificados pelo método de Lever (Lever, 1972), tendo-se adicionado $1,5 \mathrm{~mL}$ de solução de hidrazida do ácido $p$-hidroxibenzóico (HAPH) $1 \%$ em $\mathrm{NaOH} 0,5 \mathrm{M}$. A mistura foi mantida em água em ebulição em banho-maria, por 5 min e resfriada. A leitura das absorbâncias foi realizada a $410 \mathrm{~nm}$, em espectrofotômetro. A concentração de proteínas foi analisada pelo Método de Bradford (Bradford, 1976). A unidade de atividade da enzima foi expressa em $\mu$ Katal por miligrama de proteína, em que 1 Katal é definido como a atividade enzimática que catalisa a formação de 1 mol de equivalente-glicose por segundo (Di Piero \& Pascholati, 2004).

$\mathrm{Na}$ determinação da atividade de peroxidases, o procedimento de obtenção do extrato foi semelhante ao descrito para glucanases, tendo-se utilizado, no entanto, tampão fosfato de sódio $0,01 \mathrm{M}(\mathrm{pH}$ 6) durante a extração protéica. A atividade de peroxidases foi determinada espectrofotometricamente a $470 \mathrm{~nm}$, em mistura de reação que consistiu de $0,1 \mathrm{~mL}$ do sobrenadante e $2,9 \mathrm{~mL}$ de tampão fosfato $0,01 \mathrm{M}$ $(\mathrm{pH}$ 6) com guaiacol $0,25 \%(\mathrm{v} / \mathrm{v})$ e peróxido de hidrogênio $0,1 \mathrm{M}$. A reação ocorreu por $4 \mathrm{~min}$ a $30^{\circ} \mathrm{C}$, e as medidas de densidade óptica foram anotadas a cada $20 \mathrm{~s}$, com início 1 min após a adição do extrato ao substrato. Os resultados foram expressos em unidades de densidade óptica a $470 \mathrm{~nm} \mathrm{mg}^{-1} \mathrm{~min}^{-1}$.

Para se avaliar o efeito de quitosana sobre o crescimento micelial de $C$. lindemuthianum, a quitosana foi dissolvida em $\mathrm{HCl} 0,05 \mathrm{~N}$, com $\mathrm{pH}$ ajustado para 5,6 com $\mathrm{NaOH} 2 \mathrm{M}$, e incorporada ao meio de cultura BDA nas concentrações finais de $0,1,2,3,4$ ou $5 \mathrm{mg} \mathrm{mL}^{-1}$. As suspensões de quitosana e o meio BDA foram autoclavados separadamente, combinados após a autoclavagem, e então vertidos para as placas de Petri. Volumes iguais de ácido foram usados em todas as concentrações de quitosana, para manter a concentração de sais constante. Um disco (0,5 $\mathrm{cm}$ de diâmetro) com crescimento micelial de C. lindemuthianum foi repicado para o centro de seis placas de Petri de cada concentração de quitosana, no total de 36 placas em cada teste. As placas foram 
incubadas em câmara mantida a $25^{\circ} \mathrm{C}$, com fotoperíodo de 12 horas diárias de luz. O diâmetro de todas as colônias foi medido periodicamente, até que a colônia com a maior velocidade de crescimento atingisse a extremidade da placa. O experimento foi repetido duas vezes.

Para se avaliar o efeito de quitosana sobre a germinação de $C$. lindemuthianum, utilizaram-se $20 \mu \mathrm{L}$ de suspensão de esporos de $C$. lindemuthianum ( $2 \times 10^{5}$ esporos $\left.\mathrm{mL}^{-1}\right)$ e $20 \mu \mathrm{L}$ de suspensão de quitosana, nas concentrações $0,20,40,60,80$ e $100 \mu \mathrm{g} \mathrm{mL} \mathrm{m}^{-1}$, misturados e incubados em lâminas escavadas, a $20^{\circ} \mathrm{C}$, sob luz. Foram realizadas 4 repetições para cada tratamento. Após 60 horas de incubação, a percentagem de germinação de esporos foi avaliada em microscópio óptico, tendo-se analisado pelo menos 100 esporos em cada repetição. Considerou-se germinado o esporo com tubo germinativo com comprimento igual ou superior à largura do esporo. Esse bioensaio foi realizado três vezes.

Todos os ensaios foram conduzidos em delineamento inteiramente casualizado. Inicialmente, os dados foram analisados quanto à homogeneidade de variâncias. Nos casos de heterogeneidade, realizouse a transformação dos dados pelo cálculo da função logarítmica. Posteriormente, os dados foram submetidos à análise de variância e, quando pertinente, ao teste de Tukey, a 5\% de probabilidade.

\section{Resultados e Discussão}

As plantas de feijão com inoculação de C. lindemuthianum apresentaram-se menores, com desfolha, e as poucas folhas que permaneceram nas plantas achavam-se retorcidas. Nas plantas previamente tratadas com quitosana e, posteriormente, com inoculação do fitopatógeno, a severidade dos sintomas foi reduzida.

Inicialmente, foram testadas as doses de quitosana $0,6,12,18,24,36$ e $48 \mathrm{mg}$ por planta, das quais se observou efeito significativo sobre a severidade da antracnose no segundo trifólio, que foi previamente tratado, ao contrário do terceiro trifólio que estava protegido e não recebeu a aplicação de quitosana (Tabela 1). A aplicação de quitosana reduziu a doença no trifólio pré-tratado (efeito local), no entanto, doses a partir de $24 \mathrm{mg}$ por planta mostraram-se fitotóxicas. Com base nesse experimento, foram definidas como 9 e $18 \mathrm{mg}$ por planta as doses de quitosana a serem utilizadas no prosseguimento dos testes in vivo.
Quanto à influência do intervalo de tempo entre tratamento e inoculação, foi observado que o tratamento com quitosana, nas doses 9 ou $18 \mathrm{mg}$ por planta, 4 dias antes da inoculação, foi mais efetivo em reduzir a severidade da antracnose, em relação ao realizado 1 dia antes da inoculação (Figura 1). No menor intervalo de tempo, o tratamento com quitosana, independentemente da dose, não reduziu significativamente a severidade da antracnose, em comparação aos tratamentostestemunha. No intervalo de 4 dias, houve controle da doença nas folhas previamente tratadas (efeito local) com quitosana. Resultados similares foram obtidos por Eikemo et al. (2003) no patossistema do morangueiro e

Tabela 1. Efeito de doses de quitosana sobre a severidade da antracnose e observação de fitotoxicidade em plantas de feijão tratadas com quitosana e, após cinco dias, submetidas à inoculação de Colletotrichum lindemuthianum ${ }^{(1)}$.

\begin{tabular}{cccl}
\hline $\begin{array}{c}\text { Quitosana } \\
\text { (mg por planta) }\end{array}$ & \multicolumn{2}{c}{ Severidade da antracnose (notas) } & Fitotoxicidade \\
\cline { 2 - 3 } & Efeito local & Efeito sistêmico & \\
\hline 0 & $6,7 \pm 0,9$ & $8,7 \pm 0,6$ & Ausente \\
6 & $4,9 \pm 1,4$ & $8,1 \pm 1,0$ & Ausente \\
12 & $3,2 \pm 0,9$ & $8,4 \pm 1,2$ & Ausente \\
18 & $2,2 \pm 0,4$ & $7,4 \pm 0,8$ & Ausente \\
24 & $2,4 \pm 1,2$ & $7,8 \pm 1,4$ & Baixa \\
36 & $2,9 \pm 0,9$ & $8,8 \pm 0,3$ & Alta \\
48 & $3,0 \pm 1,2$ & $7,5 \pm 1,3$ & Alta \\
\hline
\end{tabular}

${ }^{(1)}$ Média \pm desvio-padrão, a partir de dois experimentos similares; os efeitos local e sistêmico foram avaliados nos segundos e nos terceiros trifólios, respectivamente; houve efeito local de doses de quitosana sobre a severidade da antracnose, pelo teste $\mathrm{F}$ a $5 \%$ de probabilidade.

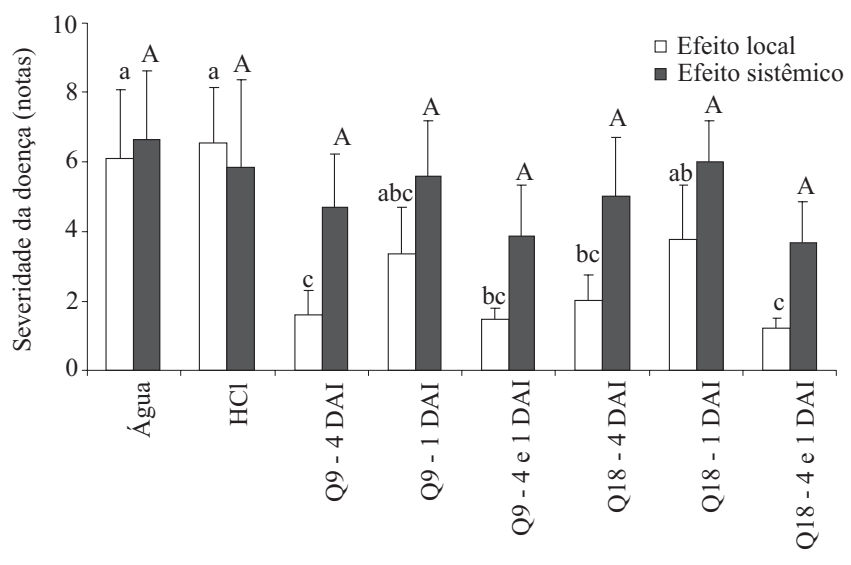

Figura 1. Efeito da aplicação de quitosana, relativa a 9 (Q9) e 18 (Q18) mg por planta de feijoeiro, em intervalos de 4 dias e 1 dia antes da inoculação (DAI), sobre a severidade da antracnose. A avaliação foi realizada 15 dias após a inoculação de $C$. lindemuthianum, por meio de uma escala de notas de 1 a 9. A barra em cada coluna representa o desviopadrão da média. Médias com letras iguais não diferem entre si pelo teste de Tukey, a 5\% de probabilidade. 
Phytophthora cactorum, em que os maiores intervalos de tempo entre o tratamento das plantas com quitosana e a inoculação também resultaram em menores índices da doença.

A aplicação de quitosana por duas vezes nas plantas, aos 4 e 1 dias antes da inoculação, não melhorou $o$ controle local da antracnose. Da mesma forma que em experimentos anteriores, não se observou efeito sistêmico da quitosana, independentemente de dose e de intervalo de tempo. Esse experimento foi conduzido por duas vezes, tendo-se encontrado as mesmas tendências.

O polissacarídeo quitosana protegeu as plantas de feijão contra a antracnose provocada por C. lindemuthianum, com porcentagem de redução da severidade da doença em torno de $70 \%$, quando se utilizaram $9 \mathrm{mg}$ por planta, 4 dias antes da inoculação.

Várias observações apontam para um modo de ação de quitosana, que atua como um fungicida natural, diretamente sobre o fungo agente causal da antracnose. Em bioensaios realizados in vitro, quitosana reduziu o crescimento micelial e a germinação de esporos de $C$. lindemuthianum. Em três experimentos independentes, concentrações de quitosana tão baixas quanto $20 \mu \mathrm{g} \mathrm{mL}^{-1}$ reduziram em aproximadamente $85 \%$ a germinação de $C$. lindemuthianum, enquanto a dose de $80 \mu \mathrm{g} \mathrm{mL}^{-1}$ inibiu totalmente o processo germinativo do fungo (Figura 2). Em outros dois

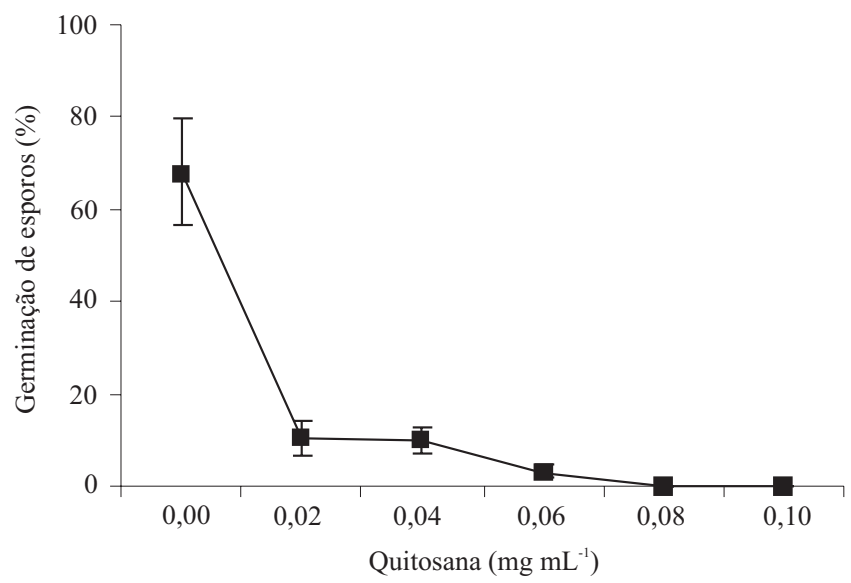

Figura 2. Efeito de quitosana sobre a germinação de esporos de Colletotrichum lindemuthianum, com 60 horas de incubação a $20^{\circ} \mathrm{C}$. Os valores representam a média de três experimentos independentes. A barra vertical representa o desvio-padrão da média. Houve efeito significativo de doses de quitosana sobre a germinação do fungo, pelo teste $\mathrm{F}$, a $5 \%$ de probabilidade. testes, observou-se redução no crescimento micelial do fungo, a partir de $1 \mathrm{mg} \mathrm{mL}^{-1}$ de quitosana colocada em meio BDA (Figura 3). O efeito inibidor teve maior magnitude com o aumento da concentração de quitosana até $3 \mathrm{mg} \mathrm{mL}^{-1}$, quando ocorreu a estabilização. Outro efeito observado foi a alteração na morfologia das colônias em placas com quitosana, que apresentavam os bordos irregulares.

Propriedades fungistáticas ou fungicidas da quitosana foram relatadas contra outros microrganismos, o que corrobora os resultados aqui apresentados. A quitosana a $50 \mu \mathrm{g} \mathrm{mL}^{-1}$ inibiu a germinação de esporos e reduziu a elongação do tubo germinativo de Botrytis cinerea (Ben-Shalom et al., 2003), enquanto a dose de $100 \mu \mathrm{g} \mathrm{mL}^{-1}$ reduziu em $75 \%$ a germinação de uredosporos de Puccinia arachidis, agente causal da ferrugem-do-amendoim (Sathiyabama \& Balasubramaniam, 1998). O crescimento de outros fungos fitopatogênicos como Alternaria alternata, Fusarium oxysporum, Rhizopus stolonifer e Penicillium spp. foi inibido em meio de cultura enriquecido com várias concentrações de quitosana (Hirano \& Nagao, 1989).

Uma hipótese sobre o mecanismo celular de ação da quitosana considera que esse polissacarídeo, de

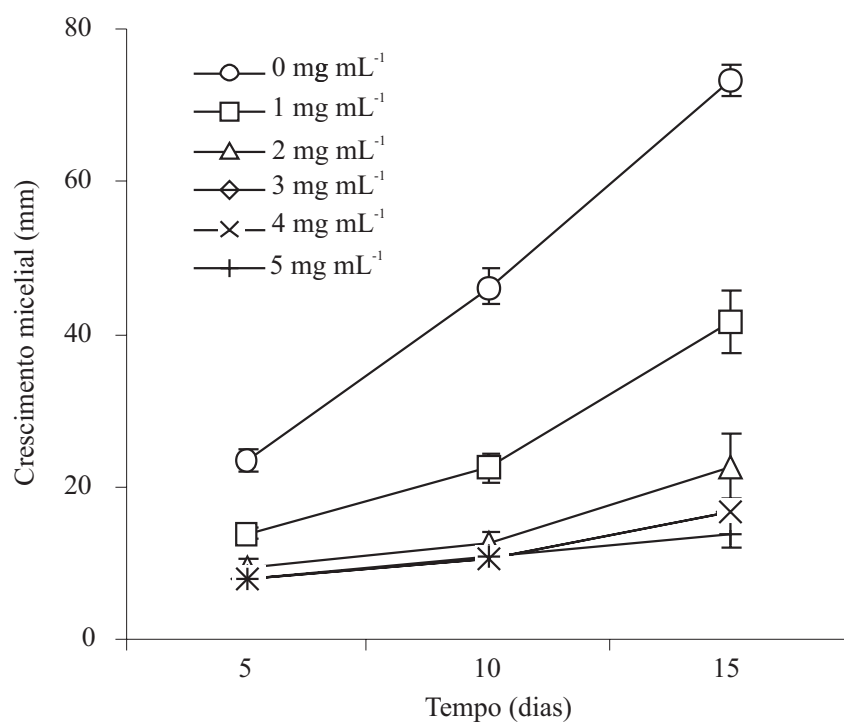

Figura 3. Efeito de quitosana sobre o crescimento micelial de Colletotrichum lindemuthianum. $\mathrm{O}$ diâmetro das colônias fúngicas foi medido aos 5, 10 e 15 dias após a repicagem do fungo em meio de cultura BDA. A barra vertical representa o desvio-padrão da média. Houve efeito significativo de doses de quitosana sobre o crescimento micelial do fungo, pelo teste $\mathrm{F}$, a $5 \%$ de probabilidade. 
alta massa molecular e cargas positivas, interfere com os resíduos carregados negativamente das macromoléculas expostas sobre a superfície celular fúngica e, dessa forma, modifica a permeabilidade da membrana plasmática (Benhamou, 1996).

Além da atuação como fungicida natural, um outro possível modo de ação da quitosana seria pela ativação de mecanismos de defesa vegetal que contribuíssem para restringir o crescimento da doença. Indução de resistência com a utilização de quitosana foi demonstrada em culturas como pepino, trigo, ervilha, tomate e amendoim, entre outras (Benhamou et al., 1998; Peter et al., 1998; Sathiyabama \& Balasubramaniam, 1998; Bhaskara Reddy et al., 1999; Hussain et al., 2003).

No presente estudo, a quitosana alterou o metabolismo relacionado à resistência em feijoeiro e provocou o aumento na atividade de beta-1,3-glucanase, em folhas previamente tratadas; essa enzima atua diretamente nas glucanas presentes na parede celular do fungo fitopatogênico inibindo o seu desenvolvimento. Esse aumento foi pouco perceptível no segundo dia após o tratamento, mas ficou evidenciado no quarto dia, quando se detectou pico na atividade enzimática (Figura 4). Nas plantas dos tratamentos-testemunha, tratadas

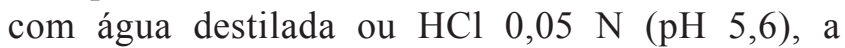
atividade de beta-1,3-glucanase foi menor e teve pouca variação ao longo do tempo de amostragem. Independentemente do tratamento prévio realizado, a inoculação do $C$. lindemuthianum nas folhas não teve efeito sobre a atividade de glucanases. Nas peroxidases, a atividade enzimática foi maior com o passar do tempo de coleta das folhas de feijão, mas sem diferenças entre os tratamentos realizados.

A elevação na atividade de glucanases também foi observada em folhas de videira e tomateiro tratadas com quitosana. $\mathrm{O}$ incremento na atividade enzimática auxiliou na proteção de videira, contra as doenças causadas por B. cinerea e Plasmopara viticola (Aziz et al., 2006), bem como na redução da severidade da requeima do tomate, provocada por Phytophthora infestans (Atia et al., 2005). Em feijoeiro, além das glucanases, a quitosana demonstrou a capacidade de ativar respostas de defesa, como a síntese de calose, e induziu resistência contra o Tobacco necrosis virus (Faoro \& Iriti, 2007) e a síntese de quitosanases e quitinases (Ben-Shalom et al., 2002).
O maior aumento na atividade de beta-1,3-glucanase nas folhas de feijão, aos 4 dias após o tratamento das plantas com quitosana, coincidiu com o intervalo de tempo entre tratamento e inoculação, em que o polissacarídeo exibiu maior proteção contra C. lindemuthianum, o que indica a participação da enzima na redução da doença. Dado que o fenômeno da resistência induzida depende de um intervalo de tempo entre a aplicação do indutor e a chegada do fitopatógeno, os resultados indicam que o controle da antracnose, em parte, se deveu à indução de resistência desencadeada pela quitosana nas folhas tratadas.

A utilização de quitosana como medida alternativa aos fungicidas, para o controle de doenças de plantas, poderá representar uma nova aplicação econômica para uma substância que é proveniente dos resíduos da

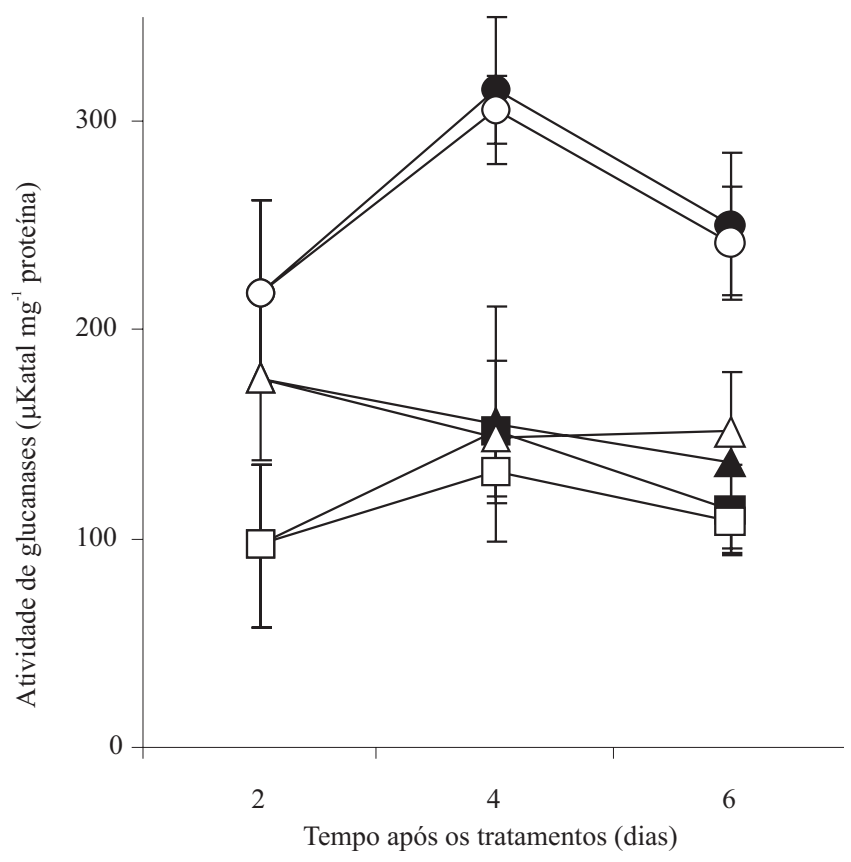

Figura 4. Atividade de beta-1,3-glucanase, em folhas de feijoeiro tratadas com água destilada $(\square, \boldsymbol{\square}), \operatorname{com~} \mathrm{HCl} 0,05 \mathrm{~N}$ - pH 5,6 ( $\triangle, \boldsymbol{\Delta})$ ou com quitosana a $18 \mathrm{mg}$ por planta $(\circ, \bullet)$, no tempo zero, e com inoculação $(\boldsymbol{\square}, \boldsymbol{\Delta}, \bullet)$ ou não $(\square, \triangle, \circ)$ do fitopatógeno Colletotrichum lindemuthianum no terceiro dia após os tratamentos. Plantas tratadas com quitosana apresentaram atividade enzimática significativamente diferente dos controles (água destilada e HCL), no quarto e sexto dia após os tratamentos, pelo teste de Tukey, a 5\% de probabilidade. 
indústria pesqueira, com reflexos positivos do ponto de vista socioeconômico e ambiental.

\section{Conclusão}

A quitosana apresenta propriedades antifúngicas contra Colletotrichum lindemuthianum, bem como a capacidade para induzir resistência ao fitopatógeno em feijoeiro.

\section{Agradecimentos}

Ao Professor Sr. Luiz Henrique Beirão, pelo fornecimento da quitosana.

\section{Referências}

ATIA, M.M.M.; BUCHENAUER, H.; ALY, A.Z.; ABOU-ZAID, M.I. Antifungal activity of chitosan against Phytophthora infestans and activation of defence mechanisms in tomato to late blight. Biological Agriculture and Horticulture, v.23, p.175-197, 2005.

AZIZ, A.; TROTEL-AZIZ, P.; DHUICQ, L.; JEANDET, P.; COURDERCHET, M.; VERNET, G. Chitosan oligomers and copper sulfate induce grapevine defense reactions and resistance to gray mold and downy mildew. Phytopathology, v.96, p.1188-1194, 2006.

BENHAMOU, N. Elicitor-induced plant defence pathways. Trends in Plant Science, v.1, p.233-240, 1996.

BENHAMOU, N.; KLOEPPER, J.W.; TUZUN, S. Induction of resistance against Fusarium wilt of tomato by combination of chitosan with an endophytic bacterial strain: ultra structure and cytochemistry of the host response. Planta, v.204, p.153-168, 1998.

BEN-SHALOM, N.; AKI, C.; ARDI, R.; PINTO, R. Elicitation effects of chitin oligomers and chitosan sprayed on the leaves of cucumber (Cucumis sativus) and bean (Phaseolus vulgaris) plants. Israel Journal of Plant Sciences, v.50, p.199-206, 2002.

BEN-SHALOM, N.; ARDI, R.; PINTO, R.; AKI, C.; FALLIK, E. Controlling gray mould caused by Botrytis cinerea in cucumber plants by means of chitosan. Crop Protection, v.22, p.285-290, 2003.

BHASKARA REDDY, M.V.; ARUL, J.; ANGERS, P.; COUTURE, L. Chitosan treatment of wheat seeds induces resistance to Fusarium graminearum and improves seed quality. Journal of Agricultural and Food Chemistry, v.47, p.1208-1216, 1999.

BIANCHINI, A.; MARINGONI, A.C.; CARNEIRO, S.M.T.P.G. Doenças do feijoeiro. In: KIMATI, H.; AMORIM, L.; REZENDE, J.A.M.; BERGAMIN FILHO, A.; CAMARGO, L.E.A. (Ed.). Manual de fitopatologia: doenças das plantas cultivadas. São Paulo: Agronômica Ceres, 2005. v.2. p.333-349.
BRADFORD, M.M. A rapid and sensitive method for the quantitation of microgram quantities of protein utilizing the principle of protein-dye binding. Analytical Biochemistry, v.72, p.248-254, 1976.

DI PIERO, R.M.; PASCHOLATI, S.F. Efeitos dos cogumelos Lentinula edodes e Agaricus blazei na interação entre plantas de tomate e Xanthomonas vesicatoria. Summa Phytopathologica, v.30, p.57-62, 2004.

EIKEMO, H.; STENSVAND, A.; TRONSMO, A.M. Induced resistance as a possible means to control diseases of strawberry caused by Phytophthora spp. Plant Disease, v.87, p.345-350, 2003.

FAORO, F.; IRITI, M. Callose synthesis as a tool to screen chitosan efficacy in inducing plant resistance to pathogens. Caryologia, v.60, p.121-124, 2007.

HEIL, M.; BOSTOCK, R.M. Induced systemic resistance (ISR) against pathogens in the context of induced plant defences. Annals of Botany, v.89, p.503-512, 2002.

HIRANO, A.; NAGAO, N. Effects of chitosan, pectic acid, lysozyme and chitinase on the growth of several phytopathogens. Agricultural and Biological Chemistry, v.53, p.3065-3066, 1989.

HUSSAIN, A.A.; ABO-GHALIA, H.H.; MOUSA, S.Y. Biological control of Fusarium wilt of pea plant grown on soil amended with chitin waste by application of rhizobacteria for chitinolytic activity and induced resistance. African Journal of Mycology and Biotechnology, v.11, p.1-24, 2003.

LEE, S.; CHOI, H.; SUH, S.; DOO, I.S.; OH, K.Y.; CHOI, E.J.; TAYLOR, T.S.; LOW, P.S.; LEE, Y. Oligogalacturonic acid and chitosan reduce stomatal aperture by inducing the evolution of reactive oxygen species from guard cells of tomato and Commelina communis. Plant Physiology, v.121, p.147-152, 1999.

LEVER, M. A new reaction for colorimetric determination of carbohydrates. Analytical Biochemistry, v.47, p.273-279, 1972.

LIN, W.; HU, X.; ZHANG, W.; ROGERS, W.J.; CAI, W. Hydrogen peroxide mediates defence responses induced by chitosans of different molecular weights in rice. Journal of Plant Physiology, v.162, p.937-944, 2005.

LOFFAGUEN, J.C.; TALAMINI, V.; STADNIK, M.J. Identificação da raça 73 de Colletotrichum lindemuthianum, agente causal da antracnose do feijoeiro, em dois municípios do Alto Vale do Itajaí, SC. Agropecuária Catarinense, v.18, p.87-89, 2005.

MANANDHAR, H.K.; JØRGENSEN, H.J.L.; MATHUR, S.B.; SMEDEGAARD-PETERSEN, V. Suppression of rice blast by preinoculation with avirulent Pyricularia oryzae and the nonrice pathogen Bipolaris sorokiniana. Phytopathology, v.88, p.735-739, 1998.

PETER, V.; VÅRUM, K.M.; DOMARD, A.; GUEDDARI, N.E. el; MOERSCHBACHER, B.M. Comparison of the ability of partially $N$-acetylated chitosan and chitooligosaccharides 
to elicit resistance reactions in wheat leaves. Plant Physiology, v.118, p.1353-1359, 1998.

RAVA, C.A.; MOLINA, J.; KAUFFMAN, M.; BRIONES, I. Determinación de razas fisiológicas de Colletotrichum lindemuthianum en Nicaragua. Fitopatologia Brasileira, v.18, p.388-391, 1993.

RHOADES, J.; ROLLER, S. Antimicrobial actions of degraded and native chitosan against spoilage organisms in laboratory media and foods. Applied and Environmental Microbiology, v.66, p.80-86, 2000.
SATHIYABAMA, M.; BALASUBRAMANIAM, R. Chitosan induces resistance components in Arachis hypogaea against leaf rust caused by Puccinia arachidis. Crop Protection, v.17, p.307-313, 1998.

SHAHIDI, F.; ARACHCHI, J.K.V.; JEON, Y.J. Food applications of chitin and chitosans. Trends Food Science and Technology, v.10, p.37-51, 1999.

SIGNINI, R. Estudo das relações estrutura/propriedades de quitina e quitosana. 2002. 167p. Tese (Doutorado) - Instituto de Química de São Carlos, São Carlos, SP.

Recebido em 14 de dezembro de 2007 e aprovado em 19 de agosto de 2008 